\title{
Age-of-acquisition norms for a set of 1,749 Portuguese words
}

\author{
Manuela L. Cameirão and Selene G. Vicente \\ University of Porto, Porto, Portugal
}

\begin{abstract}
Age of acquisition (AoA) is an important psycholinguistic variable that affects the speed and accuracy of lexical processing in tasks such as word naming, picture naming, and lexical decision. In the present work, we collected AoA ratings for 1,749 Portuguese words (nouns, verbs, adjectives, and adverbs), using a 9-point scale that was first proposed by Carroll and White (1973). We analyzed the relation between AoA ratings and other psycholinguistic variables (length measures, neighborhood density, written-word frequency, familiarity, imageability, and concreteness), and we assessed reliability by correlating our ratings with those from other databases presented for Portuguese, English, Spanish, and Italian. The full database can be downloaded from http://brm .psychonomic-journals.org/content/supplemental.
\end{abstract}

In 1973, Carroll and White showed that words acquired earlier in life tend to be processed faster and more accurately than later acquired words in a picture naming task. From that moment on, age of acquisition (AoA) was considered to be a relevant psycholinguistic variable, and several experimental studies have replicated the effect found by Carroll and White in many paradigms (e.g., picture naming - Barry, Morrison, \& Ellis, 1997; Holmes \& Ellis, 2006; Lambon Ralph \& Ehsan, 2006; written-word naming-Brysbaert, Lange, \& Van Wijnendaele, 2000; Monaghan \& Ellis, 2002a, 2002b; Morrison \& Ellis, 1995, 2000; lexical decision-Gerhand \& Barry, 1999; Turner, Valentine, \& Ellis, 1998). In fact, AoA seems to be the main variable that influences the speed of lexical processing, and its effect remains even when other variables, such as cumulative frequency, are controlled (Pérez, 2007). Recently, an extensive study conducted by Cortese and Khanna (2007) reanalyzed the results from several studies (a total of 2,343 English words) and demonstrated that AoA accounts for unique variance in reading aloud and lexical decision performance, in comparison with other variables, such as length and frequency. The AoA effect is consistent across languages and has been demonstrated in English (see, e.g., Lambon Ralph \& Ehsan, 2006), Japanese (Havelka \& Tomita, 2006; Yamazaki, Ellis, Morrison, \& Lambon Ralph, 1997), Chinese (Chen, Zhou, Dunlap, \& Perfetti, 2007), Spanish (Cuetos \& Barbón, 2006), Turkish (Raman, 2006), French (Bonin, Barry, Méot, \& Chalard, 2004), Dutch (Brysbaert et al., 2000), and Portuguese (Vicente, 2004; Vicente, Castro, \& Walley, 2008). It is also consistent throughout the entire life span, since it has been found in children (D'Amico, Devescovi, \& Bates, 2001), young adults, and older subjects (Barry, Johnston, \& Wood, 2006). Similarly, early acquired words are the last to deteriorate in neuropsychological disorders such as Alzheimer's disease (Sartori, Lombardi, \& Mattiuzzi, 2005) and aphasia (Hirsh \& Ellis, 1994). These studies highlight the vital importance of AoA in lexical processing and emphasize the need to control AoA in experimental and neuropsychological studies. For that purpose, researchers need to have access to AoA norms.

There are two ways of collecting AoA data: (1) using adult estimates (see, e.g., Bird, Franklin, \& Howard, 2001; Marques, Fonseca, Morais, \& Pinto, 2007) or (2) analyzing the performance of children in naming tasks (e.g., Chalard, Bonin, Méot, Boyer, \& Fayol, 2003). In the first method, adults are asked to estimate the age at which they possibly learned a given word. In the second method, the experimenter presents pictures to children of different age cohorts, and the average AoA is usually calculated when at least $75 \%$ of the children can name the picture (Morrison, Chappell, \& Ellis, 1997). It has been shown that adult estimates are as valid and reliable as the data collected with children (Morrison et al., 1997) and that the norms provided by the two methods are highly correlated (Ghyselinck, De Moor, \& Brysbaert, 2000; Morrison et al., 1997; Pind, Jónsdóttir, Gissurardóttir, \& Jónsson, 2000). Moreover, the correlations between the two types of norms are still significant even when other variables, such as familiarity, frequency, and phonological length, are controlled (Bonin et al., 2004). So, when it is not possible to obtain objective data, adult estimates seem to be a valid and reliable AoA measure.

Current lexical databases of AoA norms use both methods. Table 1 summarizes the main AoA norms that have been published since 1997. There is only one published lexical database for Portuguese (Marques et al., 2007). In that database, the authors collected AoA estimates for 834

S. G.Vicente, svicente@fpce.up.pt 
Table 1

Main Age-of-Acquisition Norms That Have Been Published Since 1997

\begin{tabular}{|c|c|}
\hline Language & Authors and Types of Norms \\
\hline Dutch & $\begin{array}{l}\text { De Deyne \& Storms }(2007)-309 \text { nouns } \\
\text { Ghyselinck, De Moor, \& Brysbaert }(2000)-2,816 \text { nouns }\end{array}$ \\
\hline English & $\begin{array}{l}\text { Cortese \& Khanna (2008)-3,000 monosyllabic words } \\
\text { Stadthagen-Gonzalez \& Davis }(2006)-1,526 \text { words } \\
\text { Bird, Franklin, \& Howard }(2001)-2,642 \text { words, including verbs and function words } \\
\text { Morrison, Chappell, \& Ellis }(1997)-297 \text { pictures }\end{array}$ \\
\hline French & $\begin{array}{l}\text { Bonin, Perret, Méot, Ferrand, \& Mermillod (2008)-105 celebrities’ pictures } \\
\text { Ferrand et al. (2008)-1,493 monosyllabic words } \\
\text { Hazard, De Cara, \& Chanquoy (2007)-110 pictures } \\
\text { Schwitter, Boyer, Méot, Bonin, \& Laganaro (2004)-112 action pictures } \\
\text { Chalard, Bonin, Méot, Boyer, \& Fayol }(2003)-230 \text { pictures }\end{array}$ \\
\hline Icelandic & Pind, Jónsdóttir, Gissurardóttir, \& Jónsson (2000)—260 pictures \\
\hline Italian & $\begin{array}{l}\text { Barbarotto, Laiacona, \& Capitani }(2005)-80 \text { concrete nouns } \\
\text { Barca, Burani, \& Arduino (2002)-626 nouns }\end{array}$ \\
\hline Portuguese (European) & Marques, Fonseca, Morais, \& Pinto (2007) — 834 concrete and abstract nouns \\
\hline Spanish & $\begin{array}{l}\text { Cuetos \& Barbón (2006) }-240 \text { words } \\
\text { Pérez \& Navalón }(2005)-175 \text { nouns }\end{array}$ \\
\hline
\end{tabular}

Note-The database languages are presented in alphabetic order.

concrete and abstract nouns. There are no AoA norms for Portuguese words from other grammatical classes. Hence, in the present work, we collected AoA estimates for Portuguese content words from four distinct grammatical classes (nouns, verbs, adjectives, and adverbs), with a length range from 1 to 5 orthographic syllables. Our main goals were to compile AoA norms for a large set of Portuguese words $(N=1,749)$, in order to analyze the AoA distribution as a function of grammatical class and word length, and to explore the relation between AoA and other psycholinguistic variables, such as neighborhood density and frequency. We hope that these norms are useful for researchers who wish to run experimental and neuropsychological studies that manipulate grammatical class and length.

\section{METHOD}

\section{Participants}

A total of 685 undergraduate students from the University of Porto, Portugal (144 male; mean age $=20.45, S D=2.4$, range $=$ $18-30$ years) participated in this study to obtain course credit. They were all native speakers of European Portuguese.

\section{Material}

A total of 1,749 Portuguese content words were selected from four distinct grammatical classes: 1,008 nouns $(57.63 \%), 373$ verbs (21.32\%), 332 adjectives (18.98\%), and 36 adverbs (2.06\%). This distribution by grammatical class is quite similar to the one proposed for the overall European Portuguese lexicon by Gomes and Castro (2003), which indicates that nouns account for $56 \%$ of the words, that adjectives and verbs each are about $20 \%$ of the words, and that about $3 \%$ of the corpus is constituted by adverbs. All of the 1,749 words have 1 to 5 orthographic syllables $(1$ syllable $=14$ words; 2 syllables $=266$ words $; 3$ syllables $=622$ words $; 4$ syllables $=566$ words; and 5 syllables $=281$ words). The written frequencies (extracted from the Corlex database, January 2008; Nascimento, Casteleiro, Marques, Barreto, \& Amaro, n.d.) range from 9 to 131,826, and all possible initial phonemes in Portuguese are represented.

The words were divided into 14 different paper questionnaires, containing 125 words each. The words were divided so that each questionnaire had approximately the same distribution of grammatical class and length in orthographic syllables. The questionnaires had a small introductory text in which the purposes of the study were explained, and an example was given of how to use the AoA scale. In front of each word, listed vertically, was the 9-point AoA scale first proposed by Carroll and White (1973). The points of the scale correspond to the ages (in years): $2,3,4,5,6,7-8 ; 9-10 ; 11-12 ;+13$.

\section{Procedure}

The data were collected either individually or during group classes at the universities. The instructions were presented orally and it was explained that, for each word, the participant should circle in the scale the age at which he or she possibly had learned it. The researcher emphasized that, even if the participant did not know the exact age at which he or she had acquired the word, he or she should make an estimate. On average, the participants took $15 \mathrm{~min}$ to respond to the questionnaire. Each item was estimated by a mean of 48 participants (range: $40-50$ ).

\section{RESULTS AND DISCUSSION}

The AoA data were organized in an Excel matrix, along with other relevant information for psycholinguistic and neuropsychological research (e.g., length measures, written-word frequency, neighborhood density). Table 2 summarizes the information that can be found in each one of the columns of the present database. The words in Portuguese are presented in alphabetic order, along with their English translation. For each word, we present the mean AoA and the respective standard deviation $(S D)$. The database can be downloaded from http://brm.psychonomic -journals.org/content/supplemental.

The mean AoA for the entire database was $5.73(S D=$ 1.57 ; range $=1.18-8.78$ ), corresponding to words acquired at 7-8 years of age. The distribution of mean AoA between different grammatical classes shows that there is a slight tendency for an earlier acquisition of adverbs $(M=5.31$; $S D=2.04$ ), but this can be due to the high presence in this category of typically early learned words, such as "yes," 
Table 2

Information That Is Available in the Present Lexical Database

\begin{tabular}{cll}
\hline Variable & \multicolumn{1}{c}{ Code } & \multicolumn{1}{c}{ Content } \\
\hline 1 & \# & Order number in the database \\
2 & Word & Orthographic form of the word \\
3 & English translation & English translation of the word \\
4 & Cgram & Grammatical class (noun, verb, adjective, adverb) \\
5 & Nlet & Length in letters \\
6 & NsilO & Length in orthographic syllables \\
7 & Nphom & Length in phonemes \\
8 & NSilphom & Length in phonological syllables \\
9 & OND & Number of orthographic neighbors \\
10 & OUP & Orthographic uniqueness point \\
11 & PhomND & Number of phonological neighbors \\
12 & PhomUP & Phonological uniqueness point \\
13 & Fam & Familiarity \\
14 & Imag & Imageability \\
15 & Conc & Concreteness \\
16 & Freq & Written-word frequency \\
17 & LogFreq & Transformed written-word frequency \\
18 & AoA & Average AoA of the word \\
19 & SD & Standard deviation of the AoA \\
\hline
\end{tabular}

Note-The information in rows 4 to 12 was extracted from Porlex 2.0 (Gomes \& Castro, 2003). The information in row 16 was extracted from Corlex (Nascimento, Casteleiro, Marques, Barreto, \& Amaro, n.d.). Familiarity was taken from Marques (2004), and imageability and concreteness were extracted from Marques (2005). AoA, age of acquisition.

"only," and "now," and may not reflect a general tendency of the early acquisition of adverbs. After adverbs, nouns are the earliest acquired category $(M=5.60 ; S D=1.56)$, followed by verbs $(M=5.81 ; S D=1.54)$ and adjectives $(M=6.06 ; S D=1.53)$. ANOVAs were performed (but not for adverbs, since there was a small number of words from this class), and the results show that nouns are acquired significantly earlier than verbs $[F(1)=5.00, p<.05]$ and adjectives $[F(2)=11.44, p<.005]$, and that adjectives are acquired significantly later than verbs $[F(1)=4.51$, $p<.05]$. Apart from the comparison between the mean AoA of nouns and verbs performed by Bird et al. (2001), we are not aware of any studies that compare the mean AoA between different grammatical classes. However, this advantage for early acquisition of nouns, the "nounbias hypothesis," is consistent with data provided from the language acquisition literature. Indeed, nouns are usually the first class of words acquired by young children (Gentner, 1982), although the developmental sequence and the proportion of word categories are strongly influenced by language-specific characteristics.

When we analyze mean AoA as a function of word length in orthographic syllables (OSs), we can note a clear tendency for the increase of the mean AoA as the words become longer (see Figure 1). Words with one or two OSs are typically acquired until the age of 6 (mean AoA for words with one $\mathrm{OS}=2.15, S D=0.75$; mean AoA for words with two OSs $=4.03, S D=1.42$ ); words with three or more OSs are acquired later, after the age of 7.

Table 3 presents the correlations between AoA and 11 psycholinguistic variables that are available in our database (see Table 2 for information about the variables presented in the database). Words that are learned earlier in life tend to be shorter (correlations between AoA and orthographic and phonological length measures range from .53 to .57 , $p<.05$ ), to be more frequent (correlation of -.34 between AoA and transformed written-word frequency), and to have more orthographic and phonological neighbors $(r=-.42$ and -.40 , respectively). They are also more familiar $(r=.68)$, concrete $(r=-.61)$, and imageable $(r=-.66)$ than words that are acquired later. The correlation values and their directions are in line with those presented by other studies. The correlation between the AoA and the length measures is higher than the one found for languages such as Spanish (Pérez \& Navalón, 2005; correlations between estimated AoA and length measures range between .295 and .363) and French (Chalard et al., 2003; correlation between rated AoA and number of phonemes $=.260$ ). However, it is similar to the one found for English (Bird et al., 2001; correlation between AoA and the number of syllables $=.560$ ).

We found a moderate positive correlation between the AoA and transformed written-word frequency $(r=-.34)$, which is smaller than the ones found for other languages (e.g., for English, Bird et al. [2001] reported a correlation of -.631). However, it is quite similar to those reported between the objective AoA and frequency for French (Chalard et al. [2003] found correlations that varied from -.277 to -.365 ) and for Icelandic (Pind et al. [2000] reported a correlation of -.390 ). When it comes to Portuguese, the correlation between AoA and the transformed written-word frequency reported by Marques et al. (2007) is higher $(r=-.51)$. But, if we consider the correlation between AoA and simple written-word frequency, our values and the ones reported by Marques et al. are quite similar $(r=-.27$ in our study, and $r=-.25$ in the Marques et al. [2007] study). Although there is still discussion about whether AoA is a "genuine variable" or not (Bonin et al., 2004), several studies have pointed out that AoA and frequency are independent variables, and that 


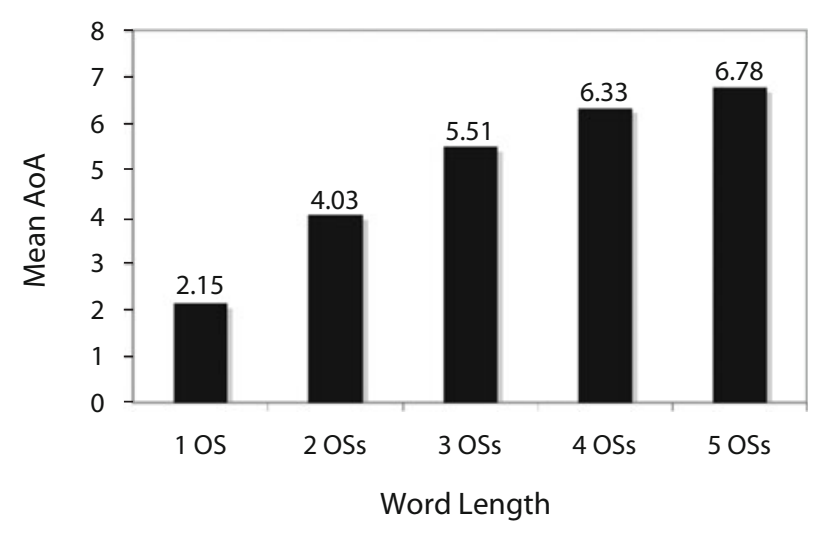

Figure 1. Mean age of acquisition (AoA) on the 9-point scale proposed by Carroll and White (1973) as a function of word length in orthographic syllables (OSs; 1-5 OSs).

AoA effects cannot be reduced to frequency effects (see, e.g., Gerhand \& Barry, 1999; Morrison \& Ellis, 1995). The weak association between AoA and frequency found for Portuguese can be due to the nature of the frequency corpus available for European Portuguese. As Zevin and Seidenberg (2002) pointed out, frequency counts are statistics that can be contaminated by factors such as the size of the corpus and the texts used in the corpus generation, which are possible sources of error. The frequency counts for European Portuguese were calculated from written material, such as books and newspapers, and the words that are commonly more frequent in this material may not be the earliest acquired in the development of oral language. Despite the weak association between AoA and frequency, we emphasize the strong correlations found between AoA and familiarity, concreteness, and imageability ( $r \mathrm{~s}=.68,-.61$, and -.66 , respectively), which are quite similar to the ones presented by Marques et al. These researchers reported a correlation between AoA and familiarity of .78, between AoA and concreteness of -.52 , and between AoA and imageability of -.69. However, we did not find the strong and positive correlation between the mean AoA and its respective standard deviation, as Marques et al. did. In our study, we found a weak negative correlation between AoA and its standard deviation for the entire database $(r=-.16, p<.05)$ and for the nouns $(r=-.17, p<.05)$. This suggests that our participants agreed slightly more in the AoA estimates of later acquired words. Perhaps this was influenced by the fact that our participants had to estimate the AoA for a heterogeneous corpus of stimuli (words from four different grammatical classes and different lengths) and that they relied on other psycholinguistic properties of the word to make an accurate estimate. As our correlational analyses report, later acquired words tend to be longer and less familiar, and this might have acted as a clue for the estimates.

In order to explore the contribution of each psycholinguistic variable to the AoA rating, two regression analyses were performed with AoA as the dependent variable. The first analysis was conducted with all of the 1,749 words and eight independent variables for which we have data (number of letters, number of orthographic syllables, number of phonemes, number of phonological syllables, orthographic neighborhood density, phonemic neighborhood density, frequency, and transformed written-word frequency). A second analysis was performed for a subset of 100 words (for which we have familiarity data) to allow a comparison with data from Marques et al. (2007). Table 4 shows the interrelations between all of the psycholinguistic variables enunciated, and Tables 5 and 6 summarize the results of multiple regression analyses. In both cases, the overall regression equations were significant $[F(8,1739)=130.76, p<.0001, R=.613 ; F(9,90)=$ $16,478, p<.0001, R=.788]$. In the first analysis, the eight independent variables taken together account for $37 \%$ of the variance, and five of them (all of the variables except the number of letters, the number of phonological syllables, and the number of phonological neighbors) make independent contributions to predicting AoA ratings (see Table 5). The best predictors were the number of orthographic syllables and transformed written-word frequency. And, as in Marques et al., the number of letters was not a significant predictor.

When we analyzed a small subset of words $(n=100)$ and added familiarity as an independent variable, the predictor variables explained $62 \%$ of the variance, but only written-word frequency turned out to be a significant predictor of rated AoA. These results are at odds with those presented by Marques et al. (2007), in which familiarity and transformed written-word frequency were significant predictors (but written-word frequency was not analyzed in the model). On the other hand, in Ferrand et al. (2008) and Bird et al. (2001), frequency was a significant predictor of rated AoA.

Finally, in order to assess the reliability of our AoA ratings, we correlated them with other published norms for Portuguese (Marques et al., 2007), English (Bird et al., 2001), Spanish (Cuetos \& Barbón, 2006), and Italian

Table 3

Correlations Between Age of Acquisition (AoA) and 11 Variables Presented in the Database

$\begin{array}{lc}\text { Variable } & \text { Correlation With AoA } \\ \text { Nlet } & .56 \\ \text { NsilO } & .56 \\ \text { Nphom } & .57 \\ \text { NSilphom } & .53 \\ \text { OND } & -.42 \\ \text { PhomND } & -.40 \\ \text { Freq } & -.27 \\ \text { LogFreq } & -.34 \\ \text { Fam } & .68 \\ \text { Conc } & -.61 \\ \text { Imag } & -.66\end{array}$

Note-All correlations are significant at $p<.05$. Please note that the higher the familiarity score, the less familiar the object. The 11 variables are number of letters (Nlet), number of orthographic syllables (NsilO), number of phonemes (Nphom), number of phonological syllables (NSilphom), number of orthographic neighbors (OND), number of phonological neighbors (PhomND), written-word frequency (Freq), transformed written-word frequency (LogFreq), familiarity (Fam), concreteness (Conc), and imageability (Imag). 
Table 4

Correlations Between 12 Psycholinguistic Variables Presented in the Database

\begin{tabular}{|c|c|c|c|c|c|c|c|c|c|c|c|c|}
\hline & 1 & 2 & 3 & 4 & 5 & 6 & 7 & 8 & 9 & 10 & 11 & 12 \\
\hline 1. AoA & & .56 & .56 & .57 & .53 & -.42 & -.40 & -.27 & -.34 & .68 & -.61 & -.66 \\
\hline 2. Nlet & & & .88 & .95 & .87 & -.55 & -.54 & -.24 & -.40 & .21 & -.41 & -.41 \\
\hline 3. NsilO & & & & .88 & .93 & -.52 & -.52 & -.26 & -.45 & $.17^{*}$ & -.34 & -.35 \\
\hline 4. Nphom & & & & & .87 & -.54 & -.56 & -.24 & -.40 & $.15^{*}$ & -.37 & -.40 \\
\hline 5. NSilphom & & & & & & -.50 & -.50 & -.25 & -.42 & $.13^{*}$ & -.33 & -.35 \\
\hline 6. OND & & & & & & & .87 & .22 & .27 & -.21 & .38 & .39 \\
\hline 7. PhomND & & & & & & & & .21 & .28 & $-.13^{*}$ & .33 & .35 \\
\hline 8. Freq & & & & & & & & & .18 & $.01^{*}$ & $.06^{*}$ & $.05^{*}$ \\
\hline 9. LogFreq & & & & & & & & & & $-.14^{*}$ & $.17^{*}$ & $.24^{*}$ \\
\hline 10. Fam & & & & & & & & & & & -.79 & -.85 \\
\hline 11. Conc & & & & & & & & & & & & -.92 \\
\hline 12. Imag & & & & & & & & & & & & \\
\hline
\end{tabular}

Note-All correlations are significant at $p<.05$, except those marked with *. The 12 variables are age of acquisition (AoA), number of letters (Nlet), number of orthographic syllables (NsilO), number of phonemes (Nphom), number of phonological syllables (NSilphom), number of orthographic neighbors (OND), number of phonological neighbors (PhomND), written-word frequency (Freq), transformed written-word frequency (LogFreq) $(N=1,749)$, familiarity (Fam) $(n=100)$, concreteness (Conc), and imageability (Imag) $(n=48)$.

Table 5

Multiple Regression Analysis With Age of Acquisition As the Dependent Variable and Eight Independent Variables

\begin{tabular}{lrrrr}
\hline Variable & \multicolumn{1}{c}{$\beta$} & \multicolumn{1}{c}{$S E$} & \multicolumn{1}{c}{$t$} & \multicolumn{1}{c}{$p$} \\
\hline Nlet & 0.569 & 0.047 & 1.201 & .229 \\
NsilO & 0.397 & 0.095 & 4.186 & $<.001$ \\
Nphom & 0.190 & 0.052 & 3.656 & $<.001$ \\
NSilphom & -0.169 & 0.095 & -1.781 & .075 \\
OND & -0.085 & 0.027 & -3.126 & .002 \\
PhomND & 0.006 & 0.027 & 0.027 & .834 \\
Freq & -0.000 & 0.000 & -5.694 & $<.001$ \\
LogFreq & -0.241 & 0.056 & -4.321 & $<.001$ \\
\hline
\end{tabular}

Note-The eight independent variables are number of letters (Nlet), number of orthographic syllables (NsilO), number of phonemes (Nphom), number of phonological syllables (NSilphom), number of orthographic neighbors (OND), number of phonological neighbors (PhomND), written-word frequency (Freq), and transformed writtenword frequency (LogFreq) $(N=1,749)$.

Table 6

Multiple Regression Analysis With Age of Acquisition As a Dependent Variable and Nine Independent Variables

\begin{tabular}{lrrrr}
\hline Variable & \multicolumn{1}{c}{$\beta$} & \multicolumn{1}{c}{$S E$} & \multicolumn{1}{c}{$t$} & $P$ \\
\hline Nlet & 0.091 & 0.187 & 0.490 & .625 \\
NsilO & 0.234 & 0.434 & 0.539 & .591 \\
Nphom & 0.302 & 0.193 & 1.570 & .120 \\
NSilphom & -0.724 & 0.443 & -1.635 & .106 \\
OND & -0.060 & 0.080 & -0.745 & .458 \\
PhomND & 0.013 & 0.108 & 0.117 & .907 \\
Freq & 1.553 & 0.186 & 8.341 & .000 \\
LogFreq & -0.000 & 0.000 & -0.725 & .471 \\
Fam & -0.358 & 0.291 & -1.232 & .221 \\
\hline
\end{tabular}

Note-The nine independent variables are number of letters (Nlet), number of orthographic syllables (NsilO), number of phonemes (Nphom), number of phonological syllables (NSilphom), number of orthographic neighbors (OND), number of phonological neighbors (PhomND), written-word frequency (Freq), transformed written-word frequency (LogFreq), and familiarity (Fam) $(n=100)$.

Table 7

Correlation Between Our Age of Acquisition (AoA) Ratings and Four Other AoA Databases

\begin{tabular}{lcc}
\hline \multicolumn{1}{c}{ Database } & Words in Common & $R$ \\
\hline Portuguese: Marques, Fonseca, Morais, \& Pinto (2007) & 106 & .944 \\
English: Bird, Franklin, \& Howard (2001) & 449 & .682 \\
Spanish: Cuetos \& Barbón (2006) & 24 & .721 \\
Italian: Barca, Burani, \& Arduino (2002) & 124 & .807 \\
\hline
\end{tabular}


(Barca, Burani, \& Arduino, 2002). These results are summarized in Table 7. Despite the variability of the amount of words in common between our database and the others analyzed (range: 24-449), all of the correlations were strong, positive, and significant (all above .682), which shows the reliability of our data.

In the present study, we collected the AoA norms for 1,749 Portuguese content words from four distinct grammatical classes: nouns, verbs, adjectives, and adverbs. We found significant correlations between the AoA and other psycholinguistic variables, such as length measures, neighborhood density, written-word frequency, and familiarity. The reliability of our AoA ratings was demonstrated by the high correlations between our norms and those available available for English, Spanish, Italian, and Portuguese. We hope that our database will be useful in experimental and neuropsychological studies.

\section{AUTHOR NOTE}

The present work was supported by the Center for Psychology of the University of Porto. We thank the students of the University of Porto and Pedro Albuquerque for help on data collection, and Frederico Gonçalves for help on data analysis. We also thank the reviewers for their helpful comments. Correspondence should be addressed to S. G. Vicente, Speech Lab, Faculty of Psychology and Education, University of Porto, Rua Doutor Manuel Pereira da Silva 4200-392 Porto, Portugal (e-mail: svicente@fpce.up.pt).

\section{REFERENCES}

Barbarotto, R., Laiacona, M., \& Capitani, E. (2005). Objective versus estimated age of word acquisition: A study of 202 Italian children. Behavior Research Methods, 37, 644-650.

Barca, L., Burani, C., \& Arduino, L. S. (2002). Word naming times and psycholinguistic norms for Italian nouns. Behavior Research Methods, Instruments, \& Computers, 34, 424-434.

Barry, C., Johnston, R. A., \& Wood, R. F. (2006). Effects of age of acquisition, age, and repetition priming on object naming. Visual Cognition, 13, 911-927.

Barry, C., Morrison, C. M., \& Ellis, A. W. (1997). Naming the Snodgrass and Vanderwart pictures: Effects of age of acquisition, frequency, and name agreement. Quarterly Journal of Experimental Psychology, 50A, 560-585.

Bird, H., Franklin, S., \& Howard, D. (2001). Age of acquisition and imageability ratings for a large set of words, including verbs and function words. Behavior Research Methods, Instruments, \& Computers, 33, 73-79.

Bonin, P., Barry, C., Méot, A., \& Chalard, M. (2004). The influence of age of acquisition in word reading and other tasks: A never ending story? Journal of Memory \& Language, 50, 456-476.

Bonin, P., Perret, C., Méot, A., Ferrand, L., \& Mermillod, M. (2008). Psycholinguistic norms and face naming times for photographs of celebrities in French. Behavior Research Methods, 40, 137-146.

Brysbaert, M., Lange, M., \& Van Wijnendaele, I. (2000). The effects of age-of-acquisition and frequency-of-occurrence in visual word recognition: Further evidence from the Dutch language. European Journal of Cognitive Psychology, 12, 65-85.

Carroll, J. B., \& White, M. N. (1973). Word frequency and age of acquisition as determiners of picture-naming latency. Quarterly Journal of Experimental Psychology, 25, 85-95.

Chalard, M., Bonin, P., Méot, A., Boyer, B., \& Fayol, M. (2003). Objective age-of-acquisition (AoA) norms for a set of 230 object names in French: Relationships with psycholinguistic variables, the English data from Morrison et al. (1997), and naming latencies. European Journal of Cognitive Psychology, 15, 209-245.

Chen, B. G., Zhou, H. X., Dunlap, S., \& Perfetti, C. A. (2007). Age of acquisition effects in reading Chinese: Evidence in favour of the arbitrary mapping hypothesis. British Journal of Psychology, 98, 499-516.

Cortese, M. J., \& Khanna, M. M. (2007). Age of acquisition predicts naming and lexical-decision performance above and beyond 22 other predictor variables: An analysis of 2,342 words. Quarterly Journal of Experimental Psychology, 60, 1072-1082.

Cortese, M. J., \& Khanna, M. M. (2008). Age of acquisition ratings for 3,000 monosyllabic words. Behavior Research Methods, 40, 791-794.

Cuetos, F., \& Barbón, A. (2006). Word naming in Spanish. European Journal of Cognitive Psychology, 18, 415-436.

D'Amico, S., Devescovi, A., \& Bates, E. (2001). Picture naming and lexical access in Italian children and adults. Journal of Cognition \& Development, 2, 71-105.

De Deyne, S., \& Storms, G. (2007). Age-of-acquisition differences in young and older adults affect latencies in lexical decision and semantic categorization. Acta Psychologica, 124, 274-295.

Ferrand, L., Bonin, P., Méot, A., Augustinova, M., New, B., PalLier, C., \& Brysbaert, M. (2008). Age-of-acquisition and subjective frequency estimates for all generally known monosyllabic French words and their relation with other psycholinguistic variables. Behavior Research Methods, 40, 1049-1054.

GentNer, D. (1982). Why nouns are learned before verbs: Linguistic relativity versus natural partitioning. In S. Kuczaj II (Ed.), Language development: Vol. 2. Language, thought, and culture (pp. 301-334). Hillsdale, NJ: Erlbaum.

Gerhand, S., \& Barry, C. (1999). Age of acquisition, word frequency, and the role of phonology in the lexical decision task. Memory \& Cognition, 27, 592-602.

Ghyselinck, M., De Moor, W., \& Brysbaert, M. (2000). Age-ofacquisition ratings for 2816 Dutch four- and five-letter nouns. Psychologica Belgica, 40, 77-98.

Gomes, I., \& CASTro, S. L. (2003). Porlex, a lexical database in European Portuguese. Psychologica, 32, 91-108.

HaVelka, J., \& Tomita, I. (2006). Age of acquisition in naming Japanese words. Visual Cognition, 13, 981-991.

Hazard, M.-C., De Cara, B., \& Chanquoy, L. (2007). Normes d'âge d'acquisition objectif des mots et recherche de prédicteurs: Importance du choix de la base de fréquence lexicale. L'Année Psychologique, 107, 427-457.

Hirsh, K. W., \& Ellis, A. W. (1994). Age of acquisition and lexical processing in aphasia: A case study. Cognitive Neuropsychology, 11, 435-458.

Holmes, S. J., \& Ellis, A. W. (2006). Age of acquisition and typicality effects in three object processing tasks. Visual Cognition, 13, 884-910.

Lambon Ralph, M. A., \& Ehsan, S. (2006). Age of acquisition effects depend on the mapping between representations and the frequency of occurrence: Empirical and computational evidence. Visual Cognition, 13, 928-948.

Marques, J. F. (2004). Normas de familiaridade para substantivos comuns [Familiarity norms for common nouns]. Laboratório de Psicologia, 2, 5-19.

Marques, J. F. (2005). Normas de imagética e concreteza para substantivos comuns [Imageability and concreteness norms for common nouns]. Laboratório de Psicologia, 3, 65-75.

Marques, J. F., Fonseca, F. L., Morais, A. S., \& Pinto, I. A. (2007). Estimated age of acquisition norms for 834 Portuguese nouns and their relation with other psycholinguistic variables. Behavior Research Methods, 39, 439-444.

Monaghan, J., \& Ellis, A. W. (2002a). Age of acquisition and the completeness of phonological representations. Reading \& Writing, 15, 759-788.

Monaghan, J., \& Ellis, A. W. (2002b). What exactly interacts with spelling-sound consistency in word naming? Journal of Experimental Psychology: Learning, Memory, \& Cognition, 28, 183-206.

Morrison, C. M., Chappell, T. D., \& Ellis, A. W. (1997). Age of acquisition norms for a large set of object names and their relation to adult estimates and other variables. Quarterly Journal of Experimental Psychology, 50A, 528-559.

MorRISON, C. M., \& ELLIS, A. W. (1995). Roles of word frequency and age of acquisition in word naming and lexical decision. Journal of Experimental Psychology: Learning, Memory, \& Cognition, 21, 116-133.

Morrison, C. M., \& Ellis, A. W. (2000). Real age of acquisition effects 
in word naming and lexical decision. British Journal of Psychology, 91, 167-180.

Nascimento, M. F. B., Casteleiro, J. M., Marques, M. L. G., BarReto, F., \& AmARo, R. (n.d.). Léxico multifuncional computorizado do português contemporâneo. Available: www.clul.ul.pt/index.php.

Pérez, M. A. (2007). Age of acquisition persists as the main factor in picture naming when cumulative word frequency and frequency trajectory are controlled. Quarterly Journal of Experimental Psychology, 60, 32-42.

PÉrez, M. A., \& NaVAlón, C. (2005). Objective-AoA norms for 175 names in Spanish: Relationships with other psycholinguistic variables, estimated AoA, and data from other languages. European Journal of Cognitive Psychology, 17, 179-206.

Pind, J., JónsDótTir, H., GissuraRdótTir, H., \& JónsSON, F. (2000). Icelandic norms for the Snodgrass and Vanderwart (1980) pictures: Name and image agreement, familiarity, and age of acquisition. Scandinavian Journal of Psychology, 41, 41-48.

RAMAN, I. (2006). On the age-of-acquisition effects in word naming and orthographic transparency: Mapping specific or universal? Visual Cognition, 13, 1044-1053.

Sartori, G., Lombardi, L., \& Mattiuzzi, L. (2005). Semantic relevance best predicts normal and abnormal name retrieval. Neuropsychologia, 43, 754-770.

Schwitter, V., Boyer, B., Méot, A., Bonin, P., \& Laganaro, M. (2004). French normative data and naming times for action pictures. Behavior Research Methods, Instruments, \& Computers, 36, 564-576.

Stadthagen-Gonzalez, H., \& Davis, C. J. (2006). The Bristol norms for age of acquisition, imageability, and familiarity. Behavior Research Methods, 38, 598-605.

Turner, J. E., Valentine, T., \& Ellis, A. W. (1998). Contrasting effects of age of acquisition and word frequency on auditory and visual lexical decision. Memory \& Cognition, 26, 1282-1291.

VICENTE, S. G. (2004). Age-of-acquisition effects in spoken word recognition by adolescents and adults [Abstract]. In Proceedings of the IX Conference of the European Association for Research on Adolescence, EARA (p. 101).

Vicente, S. G., Castro, S. L., \& Walley, A. (2008). Neighborhood density and the special role of age-of-acquisition in spoken word recognition in Portuguese. [Abstract]. International Journal of Psychology, 43, 701 .

Yamazaki, M., Ellis, A. W., Morrison, C. M., \& Lambon Ralph, M. A. (1997). Two age of acquisition effects in the reading of Japanese Kanji. British Journal of Psychology, 88, 407-421.

Zevin, J. D., \& Seidennerg, M. S. (2002). Age of acquisition effects in word reading and other tasks. Journal of Memory \& Language, 47, 1-29.

\section{SUPPLEMENTAL MATERIALS}

The word norms discussed in this article may be downloaded from http://brm.psychonomic-journals.org/content/supplemental.

(Manuscript received March 4, 2009;

revision accepted for publication November 8, 2009.) 